\title{
UnderApp: A System For Remote Monitoring Of Landslides Based On Wireless Underground Sensor Networks
}

\author{
Creyton B. de M. Ferreira \\ creytonbarretobmf@gmail.com \\ CEFET/RJ
}

\author{
André Felipe de A. Monteiro \\ andre.monteiro@cefet-rj.br \\ CEFET/RJ
}

\author{
Viviane F. Peixoto \\ vivianepeixoto989@gmail.com \\ UFRJ \\ Laura Silva de Assis
laura.assis@cefet-rj.br \\ CEFET/RJ
}

\author{
Jorge Augusto G. de Brito \\ jagb90@gmail.com \\ PPCIC-CEFET/RJ
}

\author{
Felipe da R. Henriques \\ felipe.henriques@cefet-rj.br
}

CEFET/RJ

\begin{abstract}
Every year several landslides are observed in Brazil, causing a major impact on the population which lives in risk areas. These events are permanent concerns for the local population, and also for the authorities responsible for monitoring the risk areas. This work presents UnderApp, a system for remote monitoring of landslides based on a Wireless Underground Sensor Network (WUSN). The sensor network is responsible to collect data in real time about rainfall and soil moisture, which are the main metrics for predicting the eminence of landslides. Then, the collected data is stored in a Web Server and sent to an App designed for smartphones to provide the data visualization by the local population and public authorities. A prototype was implemented and initial tests were performed to ratify the feasibility of the data collection and storage. Moreover, the App interface and its main features are presented as well.
\end{abstract}

\section{KEYWORDS}

wireless underground sensor network, web systems, mobile computing, landslides.

\section{INTRODUCTION}

The landslides are a relevant concern in Brazil since many cities have a similar tropical landscape with mountain chains and hills, such as Rio de Janeiro, Recife, Belo Horizonte, among others. The major impact of the landslides is on the population who lives in risk areas. Most of the times these events cause death and destruction, and an agile response from the governmental authorities is required in order to deal with a lot of emergency calls and rescue operations. Many cities implement a monitoring system based on rainfall rate, which triggers a warning siren in risk areas when a maximum threshold of rainfall is achieved. Then, once the siren is heard, the local population must initiate an evacuation process to avoid fatalities. Each risk area has its own maximum threshold of rainfall according to the characteristics of the terrain (soil composition, types of vegetation, inclination of the slopes, etc.). However, this approach lacks in efficiency, since many deaths were observed in recent landslides in Brazil.

In: XVI Workshop de Trabalhos de Iniciação Científica (WTIC 2019), Rio de Janeiro, Brasil. Anais Estendidos do Simpósio Brasileiro de Sistemas Multimídia e Web (WebMedia). Porto Alegre: Sociedade Brasileira de Computação, 2019.

ISSN 2596-1683
To improve the monitoring system efficiency, more data should be collected and analyzed, such as soil moisture, for instance. Furthermore, these complementary data collected must be taken into account on the decision-making process to inform the local population about an eminence of landslides. The use of a Wireless Sensor Network (WSN), enables a more comprehensive data collection in real time from the risk areas, and is presented in several works in literature, as described in [14] and [6]. These works adoption the paradigms of Smart Cities [4] and Internet of Things [3], performing remote monitoring and processing of the data collected. To implement this monitoring approach a robust infrastructure is needed, once the data must be collected, transmitted, processed and presented to the users. Moreover, the soil moisture should be collected in the underground in order to obtain real data about this metric, leading more complexity into the sensor network architecture.

In the landslides remote monitoring scenario the data collection process needs to handle the underground and the surface sensor networks, which are responsible for the soil moisture and rainfall data, respectively. Thus, there is a hybrid sensor network topology, implemented by a Wireless Underground Sensor Network (WUSN) and a traditional surface network. A gateway is responsible to transmit the collected data to a processing node, where a Web Server is running. This typical architecture is presented in Figure 1.

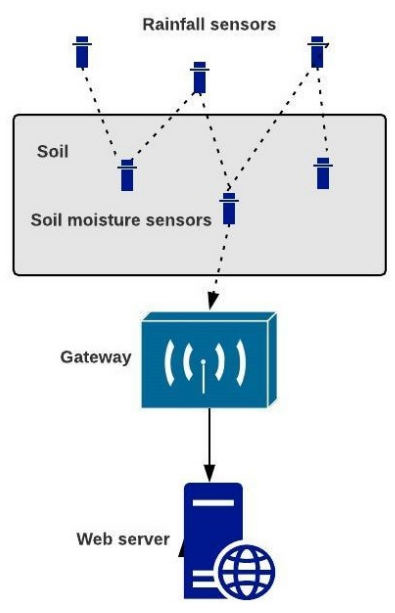

Figure 1: A typical architecture for landslides monitoring.

In this work, we present UnderApp, a remote monitoring system for risk areas of landslides. The sensor network is responsible to 
collect data in real time about rainfall and soil moisture, which are some of the most relevant metrics for predicting the eminence of landslides, as mentioned in [10] and [13]. The main difference between UnderApp and the state-of-the-art approaches described in the literature is to enable the local population to verify in real time the risk of landslides on the monitored areas. For this purpose, we propose an App for smartphones which is able to retrieve data from the Web Server and show them in a friendly manner to the users. Besides that, the local authorities have their own interface with the collected data through an API on the Web Server, enabling customized queries, longer historic, etc.

Besides describing the proposed system and its main elements, this work presents the implementation and the evaluation of an initial prototype that collects soil moisture, and then uses a Web Server for storage and processing of the collected data. Furthermore, an App is also implemented in order to visualize data and receive emergency warnings about the eminence of landslides. The paper is organized as follows: Section 2 presents the proposed monitoring system; results obtained from data gathering are discussed in Section 3; conclusions and future directions are presented in Section 4.

\section{THE PROPOSED SYSTEM}

This section presents the main characteristics of the remote monitoring system proposed. First, we analyze the infrastructure of data collection and transmission, which was implemented by a WUSN Then, we discuss the storage process in the Web Server, and we also present the App designed for smartphones which are responsible for showing the real time monitoring to users.

\subsection{Wireless Underground Sensor Network}

A typical Wireless Sensor Network (WSN) is an ad hoc network, composed by sensor devices that have the capacity to collect and process data, in different contexts (military, medical, home/industrial automation, and so on), and autonomously transmit them using a wireless infrastructure. The sensors are devices with memory and energy constraints [2]. The energy of sensor nodes is supplied by a battery with a limited lifetime. Thereby, methods that save their energy are of great importance in WSNs [9], [8]. In this work, we consider a special type of WSN, whose sensor nodes are located underground, called Wireless Underground Sensor Network (WUSN) [1].

Another relevant issue about WUSNs is the location of sensor nodes since the set of sensors must implement a connected network in order to enable reliability in data delivery. To define the best position of each sensor, the tradeoff between network performance and energy consumption have to be analyzed. If the sensor nodes are too close to each other, there may be redundant data collection, which leads to higher energy consumption due to the operation of non functional sensors. On the other hand, if the sensors are not close enough, the network can present lack of connection, leading to packet losses, and thus harming the real time monitoring process. As described in [15], the WUSNs have several specific connectivity characteristics in comparison with traditional sensor networks, such as the communication channel, for instance. Therefore, we choose an empirical approach for positioning the sensor nodes in order to evaluate the connectivity and the robustness of the data collection process, instead the using simulation tools as described in [12].

The initial results presented in this work will contribute to the development of a network framework designed for real external scenarios, aware of the climatic manifestations, considering a good usage of network resources, being these: bandwidth, energy consumption and connectivity. In order to establish a connection to the gateway (see Figure 4), we consider the IEEE 802.15.4 wireless network standard [5], commonly used in WSNs. This standard operates with low transmission rate and high energy saving, ideal for scenarios where the maximization of the network lifetime is needed [9].

\subsection{Web Server and App}

The proposed system uses the architecture earlier depicted in Fig. 1 , adding a new element to perform the data visualization by the users. This new element is an App implemented on the Android platform. Therefore, the users are able to visualize the current rates of soil moisture and rainfall, and a twelve hours historic of both metrics as well. Besides that, the App enables warning notifications about the eminence of landslides on the monitored areas. These features are shown in the screenshots presented in Fig. 2.

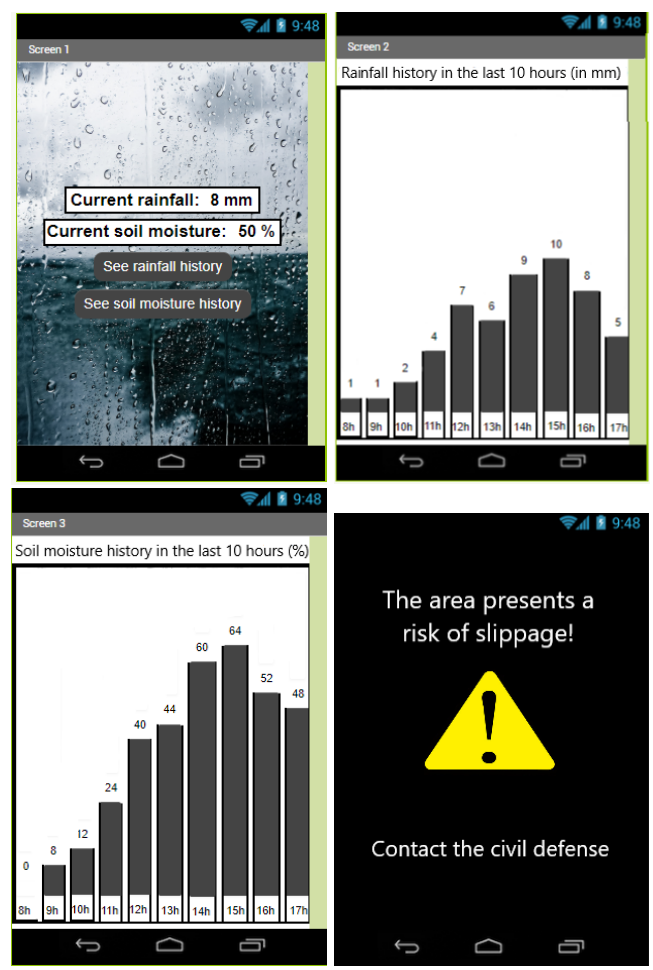

Figure 2: User interface.

As explained earlier, the Web Server is responsible to store the data collected by the WSUN. Once the data to be stored is composed only by two measured values (soil moisture and rainfall) and their timestamps, we implemented the Web Server database 
UnderApp: A System For Remote Monitoring Of Landslides Based On Wireless Underground Sensor Networks

using MongoDB. MongoDB is designed for large databases with non-relational data. As UnderApp database will present a large number of records composed by pairs with a value and its timestamp (non-relational data), MongoDB was the most suitable option. To retrieve data from the Web Server, the App sends HTTP requests and their response is performed using JSON format. This communication process is shown in Fig. 3. In addition, beyond the user interface, the Web Server has a specific API designed for the local authorities, enabling customized queries through external systems, longer historic visualization, among other features.

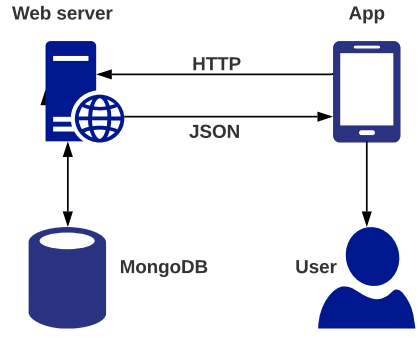

Figure 3: Communication between Web Server and App.

\section{DATA COLLECTION EVALUATION}

An experimental evaluation was performed through a prototype developed to measure soil moisture, considering the model depicted in Fig. 4. We use the Arduino MEGA 2560 micro-controller, an open source electronic prototyping platform, coupled with a humidity sensor module to check soil moisture through electrical conductivity, taking into account the water content present in the vicinity of the sensor. We periodically check the soil moisture, storing data in the memory of the Arduino. Using these elements the system is able to obtain data on the moisture content, in order to verify the soil moisture level.

In this scenario, clay soil and black soil were analyzed. The objective of this initial experiment is to collect data using a soil similar to the one that will be found in a real external scenario. The results provided by this initial prototype will support the planning of the future model to be implemented in an external scenario submitted to different climatic conditions.

The prototype of the soil moisture sensor used in the experiments is shown in Fig. 4. The general idea is to add water at a considerable distance from the sensor and analyze the behavior of soil moisture reading. The data collected are transformed into percentage of soil moisture. The soil verification time is determined according to the context. Therefore, when there is heavy rain, for example, the frequency of data collection should be dynamically increased by sensor nodes in order to perform a fine grained monitoring control. On the other hand, in sunny days, the frequency may be decreased to provide energy saving on the WUSN.

Different soils submitted to the same amount of water may present different results in relation to the humidity, in a determined period of time. Black soil has a higher water retention capacity than mineral particles, for instance, because of that, this type of soil is
Anais Estendidos do WebMedia 2019, Rio de janeiro, Brasil

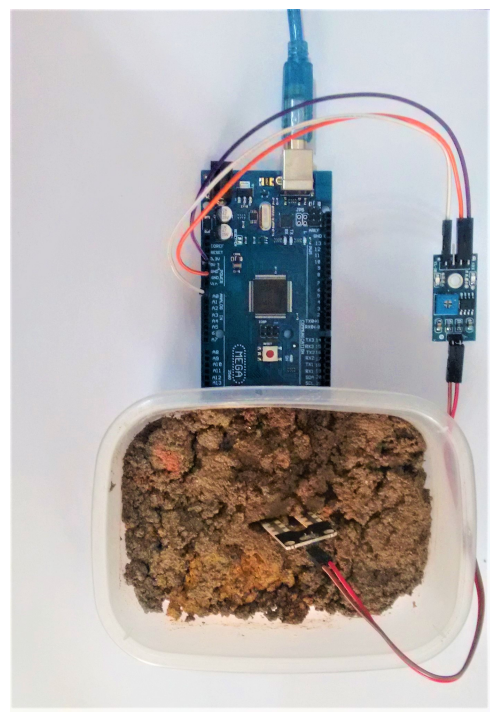

Figure 4: Prototype of the underground soil moisture sensor for data gathering.

more efficient in reducing the water effect in the friction between the mineral particles. In the clay soil, the interaction between the mineral fraction and organic matter is higher, which would result in lower availability of organic matter to interact with the water added to the soil. Consequently, clay soil retains more water. Therefore, it is possible that the humidity sensor will take a little longer to check the humidity variations close to it. This analysis helps us to decide the positions of the sensor nodes, according to the soil to be analyzed [7].

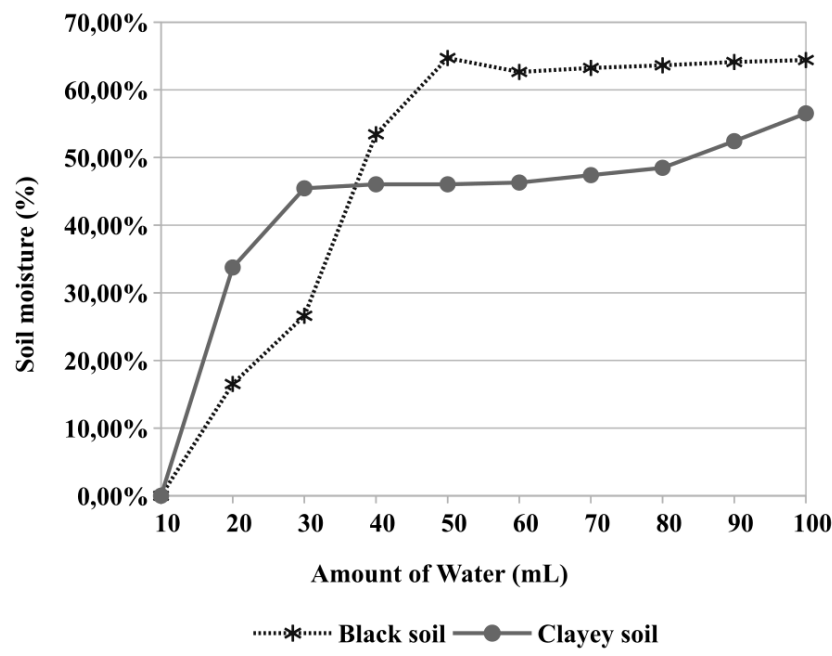

Figure 5: Soil moisture percentage in relation to the water amount in the soil (ml). For both the black and clayey soils.

In the first experiment, it was added 10 milliliters of water for every 10 seconds in each one soil type in extremely dry conditions. 
After each time was observed the resultant behavior. Fig. 5 presents the result for the percentage of soil moisture in relation to the amount of water in the soil (in $\mathrm{ml}$ ), for two distinct soils: a black and a clayey soil. It can be verified that the curve for the percentage of moisture of the black soil is more accentuated. Therefore, it can be concluded that the arrival of water in the vicinity of the sensor occurs in a short period of time. The clay soil retains the water near the surface, according to expectations. After the water arrives near the sensor, the curves tend to follow constant values.

The drying time for both soils was also considered in these initial evaluations of the proposed prototype, as we can see in Fig. 6. In this experiment, the two mentioned types of soil were subjected to 40 milliliters of water for each minute, in a total period of 300 minutes. We expect a period for the water to reach the vicinity of the sensor. This event is verified in the first minutes of the experiment, as shown in the results. Approximately 80 minutes later, the remaining water still tends to reach the vicinity of the sensor. The moisture percentage of black soil is higher than the clayey soil in the initial minutes. In addition, the black soil drying time is lower than the clay soil, as expected.

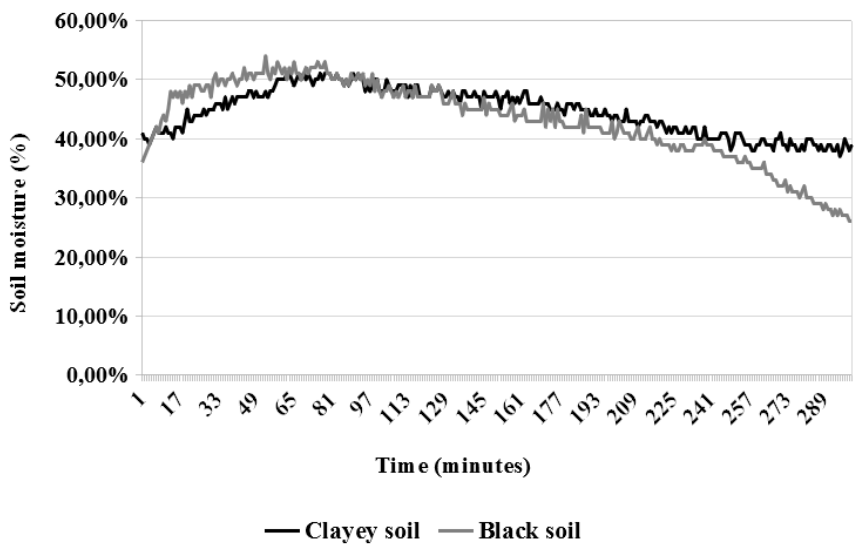

Figure 6: Drying time for both soils in study.

\section{CONCLUSION AND FUTURE DIRECTIONS}

In this work, we present UnderApp, a remote monitoring system for preventing landslides, which is based on a Wireless Underground Sensor Network (WUSN). Although this paper describes a work in progress, several important issues were addressed in our initial tests and implementation. A prototype was developed for moisture soil collection, by using a humidity sensor applied to an Arduino micro-controller. The data collected by soil moisture sensor were successfully stored in the Web Server, which sends information to an App running on smartphones and provides an API for the local authorities can obtain more detailed information in the database. The App was implemented on the Android platform and receives the soil moisture gathered by the underground sensor, and also emergency alerts if an eminence of landslides is detected. We evaluated the data collection process, and we analyzed the impact of soil type in the data gathering and the drying time.
For future works, the rainfall sensors on the surface will be added on the UnderApp, and the hybrid wireless sensor network (underground and surface) connectivity should be implemented and evaluated. To this end, we intend to evaluate the data transmission, considering the IEEE 802.15.4 wireless network standard, among others, considering the underground and the surface communication channel. Moreover, we intend to investigate how to optimize the location of the sensor nodes, in order to achieve a good coverage area, maintaining a low energy consumption by the nodes. Finally, the warning process (metrics required for decision-making and their upper thresholds, triggers to warn the local population, etc.) will be specified and evaluated considering other event repositories from the real world, such as social media [11].

The authors acknowledge the financial support from the Brazilian agencies CNPq (PIBIC) and FAPERJ (Programa Jovens Talentos).

\section{REFERENCES}

[1] Ian F. Akyildiz and Erich P. Stuntebeck. 2006. Wireless underground sensor networks: Research challenges. Ad Hoc Networks 4, 6 (2006), 669 - 686. https: //doi.org/10.1016/j.adhoc.2006.04.003

[2] I. F. Akyildiz, W. Su, Y. Sankarasubramaniam, and E. Cayirci. 2002. Wireless sensor networks: a survey. Computer Networks 38 (2002), 393-422.

[3] A. Al-Fukaha, M. Guizani, M. Mohammadi, M. Aledhari, and M. Ayyash. 2015. Internet of Things: A Survey on Enabling Technologies, Protocols and Applicationa. IEEE, 2347-2376.

[4] H. Arasteh, V. Hosseinnezhad, V. Loia, A. Tommasetti, O. Troisi, M. Shafie-khah, and P. Siano. 2016. Iot-based smart cities: A survey. In 2016 IEEE 16th International Conference on Environment and Electrical Engineering (EEEIC). 1-6. https://doi. org/10.1109/EEEIC.2016.7555867

[5] Paolo Baronti, Prashant Pillai, Vince W.C. Chook, Stefano Chessa, Alberto Gotta, and Y. Fun Hu. 2007. Wireless sensor networks: A survey on the state of the art and the 802.15.4 and ZigBee standards. Computer Communications 30, 7 (2007), 1655 - 1695. https://doi.org/10.1016/j.comcom.2006.12.020 Wired/Wireless Internet Communications.

[6] Somchai Biansoongnern, Boonyang Plungkang, and Sriwichai Susuk. 2016. Development of low cost vibration sensor network for early warning system of landslides. Energy Procedia 89 (2016), 417-420.

[7] João Alfredo Braida, José Miguel Reichert, Milton da Veiga, and Dalvan José Reinert. 2006. Resíduos vegetais na superfície e carbono orgânico do solo e suas relações com a densidade máxima obtida no ensaio Proctor. Revista Brasileira de Ciência do Solo 30, 4 (2006), 605-614.

[8] Felipe Da Rocha Henriques, Lisandro Lovisolo, and Eduardo Antônio Barros da Silva. 2019. Rate-Distortion Performance and Incremental Transmission Scheme of Compressive Sensed Measurements in Wireless Sensor Networks. Sensors 19, 2 (2019). https://doi.org/10.3390/s19020266

[9] F. R. Henriques, L. Lovisolo, and M. G. Rubinstein. 2016. DECA: distributed energy conservation algorithm for process reconstruction with bounded relative error in wireless sensor networks. EURASIP fournal on Wireless Communications and Networking 2016, 163 (July 2016), 1-18.

[10] GISELE DOS REIS MANOEL. 2010. Correlação entre chuvas e deslizamentos ocorridos durante a operação do plano preventivo de defesa civil em São Paulo, SP. (2010).

[11] Ricardo M Marcacini, Rafael G Rossi, Bruno M Nogueira, Luan V Martins, Everton A Cherman, and Solange O Rezende. 2017. Websensors Analytics: Learning to sense the real world using web news events. In Anais Estendidos do XXIII Simpósio Brasileiro de Sistemas Multimídia e Web. SBC, 169-173.

[12] João Paulo Just Peixoto and Daniel G Costa. 2018. MobSink: a Visual Mobile Wireless Sensor Networks Positioning Simulator. In Anais Estendidos do XXIV Simpósio Brasileiro de Sistemas Multimídia e Web. SBC, 103-107.

[13] Rodrigo Augusto Stabile, André Luiz Ferreira, AM de Carvalho, Alessandra Gonçalves Siqueira, and Omar Yazbek Bitar. 2013. Análise de fatores condicionantes de instabilizações em encostas como subsídio para a modelagem estatística da suscetibilidade a deslizamentos. In $14^{\circ}$ Congresso Brasileiro de Geologia de Engenharia e Ambiental-CBGE.

[14] GNL Ravi Teja, VKR Harish, D Nayeem Muddin Khan, R Bhargava Krishna, Rajesh Singh, and S Chaudhary. 2014. Land Slide detection and monitoring system using wireless sensor networks (WSN). In 2014 IEEE International Advance Computing Conference (IACC). IEEE, 149-154.

[15] H. T. H. Trang, L. T. Dung, and S. O. Hwang. 2018. Connectivity analysis of underground sensors in wireless underground sensor networks. Ad Hoc Networks 71 (2018), $104-116$. 